\title{
Plasmid profile of Neisseria gonorrhoeae in Nigeria and efficacy of spectinomycin in treating gonorrhoea
}

\author{
A O OSOBA,* N A JOHNSTON, $\dagger$ B O OGUNBANJO,* AND J OCHEI*
}

From the *Special Treatment Clinic and Venereal Diseases and Treponematoses Research Laboratories, Department of Medical Microbiology, University College Hospital, Ibadan, Nigeria, and the †London Hospital STD Reference Laboratory, Department of Medical Microbiology, The London Hospital, London

SUMMARY The prevalence of penicillinase producing Neisseria gonorrhoeae (PPNG) strains has been steadily rising in Nigeria since 1979 , and now about $80 \%$ of the strains of gonococci isolated in Ibadan are found to produce penicillinase. Spectinomycin has consequently become widely used in treating these infections. To ascertain the emergence of spectinomycin resistance, this study was undertaken to assess the in vivo susceptibilities of gonococcal strains to spectinomycin and other common antibiotics. Five hundred and twenty seven isolates were tested, of which $452(85.5 \%)$ were PPNG strains. None of the strains were found to be resistant to $100 \mu \mathrm{g}$ spectinomycin discs in vitro, whereas all 370 patients treated with the antibiotic were bacteriologically cured. Plasmid analysis shows that both "Asian" and "African" PPNG types are circulating in Nigeria. For the moment spectinomycin remains highly effective in treating gonococcal infections in west Africa.

\section{Introduction}

There has been great variation in the sensitivity of the gonococcus to antibiotics throughout the world during the past decade. The penicillinase producing strains of Neisseria gonorrhoeae (PPNG) have provided a useful marker for studies of the spread of isolates resistant to antibiotics, particularly in the Far East and African countries. For many years in Nigeria there has been an overall trend to reduction in sensitivity of gonococci to penicillin, ampicillin, and tetracycline, which has been associated with environmental selective pressures and the improper use of antibiotics. ${ }^{1}$ The increasing cost of alternative drugs, self medication, and lack of adequate treatment strategies have provided the epidemiological setting conducive to the spread of penicillinase producing strains of $N$ gonorrhoeae. The recognition of spectinomycin resistant PPNG strains ${ }^{2}$ and an increasing number of non-PPNG strains highly resistant to penicillin and other antimicrobials provide cause for concern.

In Nigeria the incidence of infections with PPNG strains has steadily increased since the first isolates

Address for reprints: Dr A O Osoba, Venereal Diseases and Treponematoses Research Laboratories, Department of Medical Microbiology, University College Hospital, Ibadan, Nigeria

Accepted for publication 5 May 1986 were identified locally in 1979 , when the incidence was $2 \cdot 7 \%{ }^{3}$ Within two years this figure had increased dramatically to $51 \cdot 7 \% .{ }^{4}$ In contrast, a survey of the incidence of PPNG strains in the United Kingdom in $1979-80^{5}$ showed an annual exponential increase with the evolution of endemic spread of infection and epidemiological evidence of an appreciable proportion of infections still being acquired overseas. Most were imported from South East Asia (50\%) and west Africa (34\%). In 1980 in the United Kingdom the prevalence of PPNG strains was low (fewer than $1 \%$ ), but subsequently in some urban areas it approached $5 \%$. The origin of these PPNG strains was correlated with penicillin resistance plasmids of two types: a 4.4 megadalton plasmid with or without an additional conjugative plasmid (24.5 megadalton) originating in South East Asia, and a 3.2 megadalton plasmid originating in west Africa. ${ }^{6}$ Many workers have used the molecular biological characteristics of these strains to identify isolates as being of "Asian" or "African" origin on the basis of plasmid size and to assess the possible geographical source of infection. More recent investigations suggest that labelling PPNG strains as "Asian" or "African" is no longer valid.?

New plasmid patterns have been identified in Africa and Europe, ${ }^{7-10}$ and multiresistant PPNG strains have spread throughout Africa. ${ }^{11}$ With the advent of penicillinase producing gonococci and their subsequent global spread spectinomycin was introduced as a 
first line drug, but there have been disturbing reports of the emergence of spectinomycin resistant gonococcal isolates elsewhere in areas of high prevalence. ${ }^{12}$ This report examines the efficacy of spectinomycin in treating gonorrhoea caused by PPNG strains in Nigeria in 1982-4 and studies of the antibiotic sensitivities and molecular characterisation of the plasmids of these strains.

\section{Patients, materials, and methods}

\section{STRAINS}

Culture of 527 gonococcal isolates obtained from patients attending the Special Treatment Centre in Ibadan yielded 452 PPNG strains. The criteria for diagnosing gonorrhoea were the identification of $\mathrm{Gram}$ negative intracellular diplococci in a smear of urethral, cervical, or vaginal exudate, and culture on ThayerMartin selective medium. The culture plates were incubated in candle extinction jars at $37^{\circ} \mathrm{C}$ for $24-48$ hours. Gonococcal strains were identified and confirmed by conventional methods. ${ }^{13}$ All gonococcal isolates were screened for penicillinase production in the department of medical microbiology, University College Hospital, Ibadan, using $6 \mu \mathrm{g}$ ampicillin discs, and $\beta$ lactamase was detected by the chromogenic cephalosporin (Nitrocefin) test. ${ }^{14}$ Sensitivities to antibiotics were measured using disc diffusion tests for penicillin, tetracycline, chloramphenicol, streptomycin, and spectinomycin: $100 \mu \mathrm{g}$ spectinomycin discs were used for susceptibility to spectinomycin, and isolates that gave an inhibition zone of more than $20 \mathrm{~mm}$ in diameter were regarded as sensitive.

\section{Surveillance of PPNG strains}

Forty nine PPNG isolates were randomly selected in 1983-4 and sent to the London Hospital sexually transmitted diseases (STD) reference laboratory for assessment of antibiotic sensitivities and molecular characterisation. On reconstitution, however, only 27 isolates had survived transportation. These strains were screened again for penicillinase production and processed for antimicrobial susceptibility and plasmid typing.

\section{ANTIBIOTIC SENSITIVITY TESTS}

The minimum inhibitory concentrations (MICs) of penicillin, tetracycline, streptomycin, cefuroxime, kanamycin, and spectinomycin were assessed by the agar plate dilution method using brain heart infusion agar (BH/G/A) free from antibiotics and enriched with $1 \%$ chemically defined supplement (Gibco) and $10 \%$ defibrinated horse blood, which was prepared in the London Hospital STD reference laboratory. Two international (World Health Organisation) reference strains with known sensitivity patterns were tested simultaneously in each batch.

\section{Antibiotics}

Reagent solutions of pencillin, tetracycline, streptomycin, kanamycin, spectinomycin, and cefuroxime were prepared and dilutions added to the medium $(\mathrm{BH} / \mathrm{G} / \mathrm{A})$ to give the required final concentrations of penicillin $(0.004-100 \mathrm{mg} / \mathrm{l})$, tetracycline $(0.06-4 \mathrm{mg} / \mathrm{l})$, spectinomycin $(10-40 \mathrm{mg} / \mathrm{l})$, cefuroxime (1-2 mg/l), streptomycin $(10-500 \mathrm{mg} / \mathrm{l})$, and kanamycin $(2-10 \mathrm{mg} / \mathrm{l})$. The inoculum size was standardised to a concentration of about $10^{8}$ organisms. A 100-fold dilution of each suspension was transferred to the appropriate antibiotic containing plate using a Steers multipoint replicator. After incubation for 24 hours the MIC was assessed as the lowest concentration of antibiotic that completely inhibited growth of the strains tested. Gonococcal strains inhibited by $0.5 \mathrm{mg} / \mathrm{l}$ or more penicillin $\mathrm{G}$ were classified as resistant.

ISOLATION AND IDENTIFICATION OF PLASMIDS

All $\beta$ lactamase producing isolates were subcultured on $\mathrm{BH} / \mathrm{G} / \mathrm{A}$ medium supplemented with $1 \mathrm{mg} / \mathrm{l}$ ampicillin. Plasmid DNA was identified by agarosegel-electrophoresis using the methods described by Eckhardt ${ }^{15}$ and Kado and Liu. ${ }^{16}$ Reference strains with plasmids of known molecular weight were included as standards. The plasmid profiles shown were identified as being African, Asian ${ }^{-}$, or Asian ${ }^{+}$(without or with the 24.5 megadalton plasmid).

\section{TREATMENT AND TEST OF CURE}

In this study 370 patients were treated with an intramuscular injection of $2 \mathrm{~g}$ spectinomycin in the gluteal region, and were advised to refrain from sexual contact and alcohol during follow up. The patients were examined 3,8 , and 21 days after treatment. The criteria used for bacteriological cure were the absence of gonococci on Gram stained smear microscopy and negative cultures. Subjects with positive cultures usually between three and 14 days after treatment were considered to be treatment failures.

\section{Results}

We tested 527 gonococcal isolates in Ibadan, and these were sensitive to spectinomycin $(100 \mu \mathrm{g})$ by disc diffusion. PPNG strains accounted for $452(85 \cdot 8 \%)$, and $75(14.2 \%)$ were non-PPNG strains, which is consistent with the increased incidence of penicillin resistant gonococcal isolates identified in Nigeria since 1979 (table I). In the study published here no spectinomycin resistant gonococci were detected by disc tests, and subsequently in the London Hospital STD reference laboratory none of the isolates was found to have MICs of spectinomycin of more than $30 \mathrm{mg} / \mathrm{l}$. Table II shows the distribution of the MICs 
TABLE I Results of screening gonococcal isolates for $\beta$ lactamase production in Ibadan, Nigeria, 1977-84

\begin{tabular}{lll}
\hline Year & $\begin{array}{l}\text { No of gonococcal } \\
\text { isolates screened }\end{array}$ & $\begin{array}{l}\text { No (\%) of PPNG } \\
\text { strains found }\end{array}$ \\
\hline 1977 & 80 & 0 \\
1978 & No screening & $32(12 \cdot 5)$ \\
1979 & 257 & $53(22 \cdot 3)$ \\
1980 & 238 & $152(50 \cdot 0)$ \\
1981 & 304 & $323(70 \cdot 2)$ \\
1982 & 460 & $320(75 \cdot 8)$ \\
1983 & 422 & $329(81 \cdot 0)$ \\
1984 & 406 & \\
\hline
\end{tabular}

and the plasmid composition of some of these PPNG isolates acquired by Africans in Nigeria. The plasmid profile of 27 randomly selected strains showed 10 Asian $^{+}$, four Asian ${ }^{-}$, and 13 African types. Table III shows an analysis of a limited number of Nigerian PPNG strains by serogrouping using monoclonal reagents (Phadebact) against WI and WII/III serogroups. The sample was small, but serogroup WII/III predominated. In the therapeutic follow up study of 370 patients (272 men and 98 women) harbouring $\beta$ lactamase producing gonococci, 30 defaulted and three were reinfected during follow up, leaving 337 patients who were assessed. The overall cure rate was $100 \%$. Thirty five $(13 \%)$ men developed postgonococcal urethritis and responded to a seven day course of tetracycline. Treatment with spectinomycin produced no adverse side effects, and patient tolerance was good.

TABLE III Plasmid typing and serogrouping of 15 penicillinase producing strains of Neisseria gonorrhoeae from Nigeria

\begin{tabular}{llll}
\hline & & \multicolumn{2}{l}{ Serogroups: } \\
\cline { 4 - 4 } $\begin{array}{llll}\text { Plasmid molecular } \\
\text { mass (megadaltons) }\end{array}$ & $\begin{array}{l}\text { No of } \\
\text { strains }\end{array}$ & WI & WII/WIII \\
\hline $2.63 \cdot 2$ & 10 & 5 & 5 \\
2.64 .424 .5 & 4 & & 4 \\
2.64 .4 & 1 & 1 & 9 \\
Total & 15 & 6 & 9 \\
\hline
\end{tabular}

TABLE II Minimum inhibitory concentrations (MICs) of six antimicrobial agents for 27 penicillinase producing Neisseria gonorrhoeae (PPNG) strains according to plasmid types

\begin{tabular}{|c|c|c|c|c|c|c|c|c|}
\hline \multirow{2}{*}{$\begin{array}{l}\text { Strain } \\
\text { No }\end{array}$} & \multirow{2}{*}{$\begin{array}{l}\text { Plasmid molecular } \\
\text { mass (megadaltons) }\end{array}$} & \multirow{2}{*}{$\begin{array}{l}\text { Plasmid } \\
\text { type }\end{array}$} & \multicolumn{6}{|c|}{ MICs (mg $h)$ of: } \\
\hline & & & Penicillin & Tetracycline & Spectinomycin & Cefuroxime & Kanamycin & Streptomycin \\
\hline 1 & 24.54 .42 .6 & $\mathrm{Asia}_{+}^{+}$ & $>100$ & 4 & 30 & 1 & 8 & $>500$ \\
\hline 2 & 24.54 .42 .6 & $\mathrm{Asia}^{+}$ & $>100$ & 2 & 30 & $i$ & 8 & $>500$ \\
\hline 3 & 24.54 .42 .6 & $\mathrm{Asia}^{+}$ & $>100$ & 4 & 30 & 2 & 10 & $>500$ \\
\hline 4 & 24.54 .42 .6 & $\mathrm{Asia}^{+}$ & $>100$ & 4 & 30 & 1 & 8 & $>500$ \\
\hline 5 & 24.54 .42 .6 & $\mathrm{Asia}^{+}$ & $>100$ & 4 & 30 & 2 & 10 & $>500$ \\
\hline 6 & 24.54 .42 .6 & $\mathrm{Asia}_{+}^{+}$ & $>100$ & 4 & 20 & 1 & 4 & $>500$ \\
\hline 7 & 24.54 .42 .6 & $\mathrm{Asia}^{+}$ & $>100$ & 4 & 20 & $i$ & 10 & $>500$ \\
\hline 8 & 24.54 .42 .6 & $\mathrm{Asia}^{+}$ & $>100$ & 2 & 25 & 1 & 10 & $>500$ \\
\hline 9 & 24.54 .42 .6 & $\mathrm{Asia}^{+}$ & $>100$ & 4 & 30 & 2 & 8 & $>500$ \\
\hline 10 & 24.54 .42 .6 & $\mathrm{Asia}^{+}$ & $>100$ & 2 & 30 & 1 & 10 & $>500$ \\
\hline 11 & 4.42 .6 & Asia $^{-}$ & $>100$ & 4 & 30 & 1 & 8 & $>500$ \\
\hline 12 & $4 \cdot 42 \cdot 6$ & Asia ${ }^{-}$ & $>100$ & 1 & 30 & 1 & 8 & $>500$ \\
\hline 13 & $4 \cdot 42 \cdot 6$ & Asia $^{-}$ & $>100$ & 4 & 30 & 1 & 8 & $>500$ \\
\hline 14 & $4.42 \cdot 6$ & $\mathrm{Asia}^{-}$ & 25 & 1 & 20 & $i$ & 8 & 10 \\
\hline 15 & 2.63 .2 & Africa & 50 & 2 & 30 & 1 & 4 & $>500$ \\
\hline 16 & 2.63 .2 & Africa & 50 & 2 & 20 & 1 & 4 & $>500$ \\
\hline 17 & $2.63 \cdot 2$ & Africa & 50 & 4 & 30 & 1 & 8 & $>500$ \\
\hline 18 & $2.63 \cdot 2$ & Africa & 100 & 1 & 20 & 1 & 8 & 10 \\
\hline 19 & 2.63 .2 & Africa & $>100$ & 2 & 25 & 1 & 8 & $>500$ \\
\hline 20 & $2 \cdot 63 \cdot 2$ & Africa & $>100$ & 1 & 25 & 1 & 8 & $>500$ \\
\hline 21 & $2.63 \cdot 2$ & Africa & $>100$ & 1 & 25 & 1 & 8 & $>500$ \\
\hline 22 & $2 \cdot 63 \cdot 2$ & Africa & $>100$ & 1 & 25 & 1 & 10 & $>500$ \\
\hline 23 & $2.63 \cdot 2$ & Africa & $>100$ & 1 & 25 & 1 & 10 & $>500$ \\
\hline 24 & $2.63 \cdot 2$ & Africa & $>100$ & 2 & 25 & 1 & 10 & $>500$ \\
\hline 25 & $2.63 \cdot 2$ & Africa & $>100$ & 2 & 25 & 1 & 10 & $>500$ \\
\hline 26 & 2.63 .2 & Africa & $>100$ & 4 & 30 & 1 & 10 & $>500$ \\
\hline 27 & 2.63 .2 & Africa & $>100$ & 2 & 30 & $i$ & 10 & $>500$ \\
\hline
\end{tabular}

All strains tested were sensitive to spectinomycin but resistant to tetracycline $(\geq 1 \mathrm{mg} / \mathrm{l})$ and streptomycin $(\geq 500 \mathrm{mg} / \mathrm{l})$ and relatively insensitive to kanamycin $(8-10 \mathrm{mg} / 1)$. 


\section{Discussion}

PPNG strains present a serious problem in many parts of the world. There is urgent need for alternative effective and inexpensive treatment to combat the threat provided by PPNG strains and non-PPNG strains with reduced sensitivity to antimicrobials. In 1982 the incidence of PPNG strains increased rapidly in west Africa, ${ }^{4}$ and the prevalence $(85 \%)$ in the study published here compares with reports from other parts of the country (Ilorin $74.2 \%$, Enugu $73 \%$, personal communication).

Both African and Asian type PPNG strains are thought to be well established and circulating freely throughout African countries, and the high levels of incidence identified in Nigeria are remarkable when compared with those of other areas of high incidence, such as the Philippines(30-40\%), ${ }^{17}$ Thailand (42\%), ${ }^{18}$ Japan (16.1\%), ${ }^{19}$ Singapore (33.5\%), ${ }^{20}$ Indonesia $(25 \%),{ }^{21}$ and the Netherlands (where there was regional variation in incidence of $4-25 \%$ of all gonococcal isolates. ${ }^{722}$ The dramatic increase of infections with PPNG strains in the Netherlands coincided with the emergence of a hybrid variant of the African strain that had acquired the large 24.5 megadalton conjugative plasmid in addition to the small $3 \cdot 2$ megadalton plasmid, which promoted greater stability and apparent selective advantage of these isolates within local gonococcal populations. Such isolates have not been documented in PPNG strains isolated in Nigeria, but eight have been identified in the STD reference laboratory of the London Hospital from patients with primary source contacts in Nigeria and Zambia (unpublished data).

In many African countries prostitution is common, there is widespread indiscriminate use of oral antibiotics, and the lack of control of the sale of antibiotics promotes high rates of treatment failure. Our studies confirmed that African PPNG strains are highly resistant to penicillin (MICs $\geq 100 \mathrm{mg} / \mathrm{l}$ ), tetracycline (MICs 1-4 mg/l), and streptomycin (MICs $\geq 500 \mathrm{mg} / \mathrm{l}$ ), and are also relatively insensitive to kanamycin (table II). In contrast, all strains tested were susceptible to spectinomycin and cefuroxime, but it is noteworthy that the MICs for spectinomycin and cefuroxime were found at the upper range of tolerance to antibiotics that is acceptable for treating gonorrhoea.

Though spectinomycin resistant PPNG strains are reported rarely throughout the world, ${ }^{212}$ nevertheless in Britain in 1982-3 at least 50 spectinomycin resistant PPNG strains were identified, mainly in the London area, and 28 of these were referred to and confirmed in the London Hospital STD reference laboratory. All the strains carried plasmids of $4.4,2.6$, and 24.5 megadaltons. So far there is no documented evidence of spectinomycin resistance associated with the treat- ment of penicillinase producing $N$ gonorrhoeae in Nigeria, but with the routine use of this antibiotic similar therapeutic problems may arise. It is purely conjectural whether and when multiple resistance to drug treatment will appear in gonococci. ${ }^{23}$

Spectinomycin is readily available in west Africa, though more expensive than penicillin. It is still highly effective against PPNG strains, as shown by this study. Every effort should be made to contain further spread of PPNG strains across tropical Africa by epidemiological surveillance and controlled trials reevaluating current treatment regimens. In this way the efficacy of alternative antimicrobial agents ${ }^{24}$ of use in areas of high prevalence may be assessed to enable the development of treatment schedules and forestall the selection of more resistant strains.

Perhaps the trends in future may be directed towards the production of a new generation antimicrobial agent that is cheap, effective, non-toxic, orally administered, and more readily acceptable in the developing countries.

We thank Upjohn (Nigeria) Ltd for a research grant to support this study, and Mrs Helen Wong and Mr Clive Jones for expert technical help.

\section{References}

1. Osoba AO, Montefiore DG, Sogbetun AO, Alausa MO, Anong $\mathrm{CN}$. Sensitivity pattem of Neisseria gonorrhoeae to penicillin and screening for $\beta$ lactamase production in Ibadan, Nigeria. British Journal of Venereal Diseases 1977;53:304-7.

2. Ashford WA, Potts DW, Adams HJU, et al. Spectinomycinresistant penicillinase producing Neisseria gonorrhoeae. Lancet 1981;ii:1035-7.

3. Osoba AO, Afoakwa SN, Twum-Danso K, Ochei J. Penicillinase producing Neisseria gonorrhoeae in West Africa. WHO/VDT/RES/GON/81 1981;No 132:1-8.

4. Osoba AO, Ogunbanjo BO. Penicillinase producing Neisseria gonorrhoeae in Nigeria. East Afr Med J 1983;60:694-8.

5. Johnston NA, Kolator B, Seth AD. A survey of $\beta$-lactamase producing gonococcal isolates reported in the United Kingdom 1979-80: the present trend. Lancet 1981;i:263-4.

6. Elwell LP, Roberts M, Mayer LW, Falkow S. Plasmidmediated beta-lactamase production in Neisseria gonorrhoeae. Antimicrob Agents Chemother 1977;11:528-33.

7. Ansink-Schipper MC, van Klingeren B, Huikeshoven MH, Woudstra RK, Dessens-Kroon M, van Wijngaarden $L J$. Epidemiology of PPNG infections in Amsterdam: analysis by auxanaographic typing and plasmid characterisation. British Journal of Venereal Diseases 1984;60:141-6.

8. Anderson B, Odugbemi T, Johnson S. Penicillinase producing Neisseria gonorrhoeae strains from Nigeria with Far Eastern type plasmid. Lancet $1982 ;$; 676.

9. Odugbemi TO, Brown ST, Biddle J, et al. Plasmid profile serogrouping and auxotyping of Neisseria gonorrhoeae isolates from Africa. British Journal of Venereal Diseases 1983;59:413.

10. Johnston NA, Kolator B. Emergence in Britain of $\beta$-lactamase producing gonococci with new plasmid combination. Lancet 1982;i:445-6. 
11. Osoba AO, Rotowa NA, Ogunbanjo BO, Ochei J. Review of penicillinase producing Neisseria gonorrhoeae in Ibadan, Nigeria, and their susceptibility to antibiotics. European Journal of Sexually Transmitted Diseases 1984;1:145-8.

12. Easmon CSF, Ison CA, Bellinger CM, et al. Emergence of resistance after spectinomycin treatment for gonorrhoea due to $\beta$-lactamase producing strains of Neisseria gonorrhoeae. $\mathrm{Br}$ Med J 1982;284:1604-5.

13. Flynn J, Waitkins SA. A serum-free medium for testing fermentation reactions in Neisseria gonorrhoeae. J Clin Pathol 1972;25:525.

14. O'Callaghan CH, Morris A, Kirby SM, Shingler AH. Novel method for detection of $\beta$-lactamase by using chromogenic cephalosporin substrate. Antimicrob Agents Chemother 1972;1:283-8.

15. Eckhardt T. A rapid method for identification of plasmid of deoxyribonucleic acid in bacteria. Plasmid 1978;1:584-8.

16. Kado CI, Liu ST. Rapid procedure for detection and isolation of large and small plasmids. J Bacteriol 1981;145:1365-73.

17. Perine PL, Morton RS, Piot P, Siegel MS, Antal GM. Epidemiology and treatment of penicillinase producing Neisseria gonorrhoeae. Sex Transm Dis 1979;6:152-8.

18. Brown S, Biddle J, Warnnissorn T, Panikabutra K, Traisupa A. Antimicrobial resistance of Neisseria gonorrhoeae in Bangkok: is single drug treatment passé? Lancet 1982;ii:366-8.

19. Yoshida S-I, Urabe S, Mizuguchi Y. Antibiotic sensitivity patterns of penicillinase-positive and penicillinase-negative strains of Neisseria gonorrhoeae isolated in Fukuoka, Japan. British Journal of Venereal Diseases 1982;58:305-7.

20. Sng EH, Lim AL, Yeo KL. Susceptibility to antimicrobials of Neisseria gonorrhoeae in Singapore: implications on the need for more effective treatment regimens and control strategies. British Journal of Venereal Diseases 1984;60:374-9.

21. Josodiwondo S. Penicillinase-producing Neisseria gonorrhoeae in Jakarta, Indonesia. British Journal of Venereal Diseases 1982;58:408.

22. van Embden JDA, van Klingeren B, Dessens-Kroon M, van Wijngaarden LJ. Emergence in the Netherlands of penicillinase-producing gonococci carrying 'Africa' plasmid in combination with transfer plasmid. Lancet 1981;i:938.

23. Sparling PF. Treatment of gonorrhea. What effect will antibiotic resistance have in the future? Sex Transm Dis 1979;6 (suppl):120-5.

24. Peeters $M$, Van Dyck E, Piot $P$. In vitro activity of the spectinomycin analog U-63366 and four quinolone derivatives against Neisseria gonorrhoeae. Antimicrob Agents Chemother 1984;26:608-9. 